\title{
Effect of Postharvest Application of Edible Coatings and Packaging on Acid Lime Fruit var. Sun Kagati 1 Quality at Ambient Storage Condition
}

\author{
Sujata Poudel ${ }^{1 *}$, Ishwori Prasad Gautam¹, Purushottam Prasad Khatiwada ${ }^{2}$, Dipendra Ghimire ${ }^{1}$, \\ Sujan Subedi ${ }^{1}$, Suprabha Pandey ${ }^{1}$, Mira Dhakal ${ }^{1}$ and Rajendra Regmi ${ }^{3}$ \\ ${ }^{1}$ National Horticulture Research Centre, Khumaltar, Lalitpur, Nepal \\ ${ }^{2}$ Value Chain Development of Fruit and Vegetables in Nepal, Hariharbhawan, Kathmandu, Nepal \\ ${ }^{3}$ Agriculture and Forestry University, Rampur, Chitwan, Nepal \\ "Corresponding Author's Email: sujatapoudel40@gmail.com \\ *Orcid ID: https://orcid.org/0000-0002-4003-1333
}

Received on: 30 September 2020, Revised on: 28 March 2021, Accepted on: 11 April 2021

\begin{abstract}
Sunkagati-1 is one of the commonly grown acid limes recommended for terai region of Nepal with main season production from Shrawan to Poush. In recent year, area of acid lime is increasing while no appropriate technology of postharvest is available for it. An experiment was carried out with an objective to assess the influence of edible oil coatings and packaging on storage life of acid lime fruit. Fruits were harvested at physiologically mature stage with smooth and shiny appearance and treated with four edible oils (coconut oil, mustard oil, sesamum oil and castor oil), liquid paraffin 10\% wax emulsion and 25 micronlow density polyethylene (LDPE) packaging. The study was conducted in completely randomized block design (CRD) with seven treatments and three replications. Fruits were kept at ambient condition $\left(20 \pm \mathbf{1 . 5 5}{ }^{\circ} \mathbf{C}, \mathbf{6 5} \pm 6.5 \% \mathrm{RH}\right)$ till 24 days and analyzed for various postharvest physical, chemical and physiological parameters after $8^{\text {th }}, 16^{\text {th }}$ and $24^{\text {th }}$ days of storage. The result showed that LDPE packaging has significant effect on reduction of physiological loss in weight (1.69\%), spoilage loss (5.17\%), higher vitamin $\mathrm{C}$ content $(60.11 \mathrm{mg} / 100 \mathrm{~g})$, Titratable acidity $(6.71 \%)$ and development of marketable color viz., 100\%yellow color. Also, coconut oil showed significantly better postharvest quality retention with reduced physiological loss in weight $(10.83 \%)$ and spoilage loss $(10.45 \%)$. This study concluded that LDPE packaging and coconut oil coating are the appropriate method to extend the storage life of acid lime in ambient condition of mid hills situation.
\end{abstract}

Keywords: Acid lime, ambient storage, oil coatings, LDPE packaging, storage life

\section{Introduction:}

Acid lime (Citrus aurantifolia) is one of the second most important citrus fruit crops in Nepal next to mandarin. According to the MoALD (2018), the net area covered by citrus fruits was 46328 ha with net production 239773 MT in which mandarin occupied $62 \%$, acid lime $19 \%$, sweet orange $15 \%$, lemon $2 \%$ and other citrus fruit $2 \%$. The total area under acid lime in Nepal is 9558 ha with production 39580 MT and productivity $7.02 \mathrm{MT} / \mathrm{ha}$. Despite very long history of acid lime cultivation in the country, only three varieties are formally registered so far. The varieties Sunkagati1 and Sunkagati 2 are recommended for terai and mid hill (upto 800 masl) and TerhathumSthaniyafor hilly region (1000-16000 masl). The main season of Nepalese 
lime production in Mid hill is Aswin to Mansir. These promising terai varietiesgive earlier harvest (Shrawan to Mansir) than the normal season production of mid hill variety. Thus the area of acid lime is increasing year wise in terai region( 32 to 52 districts) in the recent years but the production is still low (Poudel and Khatiwada, 2020).

The huge amount of acid lime has been imported yearly in the previous years from India. A total of 3795 metric ton of lime which worth about Rs. 78 corers was imported from India in the previous year which hold 96\% of total market demand (Annual Report, 2019). Also the farmers in terai and low hills areas are attracted towards the lime production as it is easier than vegetable farming, economic and can be produced for longer duration in a year. Thus federal, provincial and local governments have initiated different program from previous fiscal year to increase the area of production of acid lime in Nepal in order to import substitution in short-run and attaining selfsufficiency in long run. In the context of ever increasing are under cultivation and expansion of production areas, it is utmost importance of the postharvest technology in acid lime so that availability of acid lime can be extended in market in the lean periods which can also offer handsome price for the produce in its offseason.

In Nepal Doko, a bamboo basket is common transportationcontainerof acid lime in hilly areas. Loss in acid lime is higher in monsoon season (Ladaniya, 2015). Fruit coating and use of low-density polyethylene (LDPE) bag is a common practice in citrus fruit nowadays in different countries. The objective of study is to identify the postharvest technology which ultimately reduces the rate of internal and external fruit quality degradation after harvest and extend the storage time of acid lime to harness the good market price during the lean period.

\section{Materials and methods:}

The study was carried out at laboratory of Horticulture Research Division (HRD), Khumaltar. The fruit of acid lime variety Sunkagatil at physiological mature stage was harvested at cool hour from a farmer's field of Nawalpur district and kept overnight to remove field heat and brought to HRD, Khumaltar on the next day of harvest keeping on plastic crate safely. The fruit was kept at shade condition for pre-cooling after washing with tap water and let to dry. The experiment was set on the same day immediately after surface drying of the fruit. . The fruit was sorted for experimental unit after cleaning with dry and clean muslin cloth.The treatments used were
Liquid paraffin wax $10 \%$ emulsion, mustard oil $100 \%$, coconut oil $100 \%$, castor oil $100 \%$, sesamum oil $100 \%$, LDPE Packaging and without any treatment (control).A total of $50 \mathrm{ml}$ of edible oil was used for coating $12 \mathrm{~kg}$ fruit. An experimental unit consisted of 60 fruits. All the experimental units were kept for observation at ambient room conditionwith mean temperature $20 \pm 1.55{ }^{\circ} \mathbf{C}$ and relative humidity $65 \pm 6.5 \%$ from 3 rd to $26^{\text {th }}$ November, 2019. The storage temperature and relative humidity was recorded daily till the last day of the storage. The research was designed in Completely Randomized Design with 7 treatments and 3 replications altogether with 21 total observation.

\section{Data Collection}

The observation on various postharvest parameters was done at successive time intervals of eight days after storage. The observations were taken on physiological loss in weight, spoilage loss, total soluble solids, titratable acidity, vitamin $\mathrm{C}$, color change and shelf-life of the fruit. Two fruit from each experimental unit was used as destructive sample on each observation day for TSS, TA and vitamin C determination and ten fruit per each experimental unit was allotted as non-destructive sample.

\section{Physiological Weight Loss (PLW)}

Ten non-destructive sample of Sunkagati 1 fruits were weighed on first day and on every eightdays interval using digital balance ((SACLTEC SPB42). The difference between initial and final weight of fruit was considered as total weight loss during storage interval and expressed as percentage.

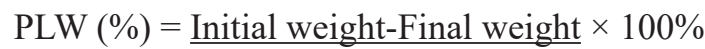 Initial weight}

\section{Total soluble solids (TSS)}

The two fruits weresqueezed using lime squeezer and the juice was extracted from the fruits. The juice was usedfor TSS determination usingPocket Brix-Acidity Meter (model: PAL-BX|ACID F5 Cat. No.7100) in ${ }^{\circ}$ Brix by placing two to three drops of clear juice on the prism surface.

\section{Titratable acidity (TA)}

The extracted juice using lime squeezer was diluted to 1:50 ratios and TA was recorded using Pocket Brix-Acidity Meter (model: PAL-BX|ACID F5 Cat. No.7100) in percentage by placing 1 to 2 drops of diluted juice on the prism surface. 


\section{Spoilage loss (SL)}

Fruits were evaluated visually for symptoms of decay at the end of each storage interval. Samples having diseased symptoms were counted. The pathogen causing decay was identified in pathology laboratory.

\section{SL $(\%)=\underline{\text { Number of Decayed fruits }} \times 100$ Number of total fruits}

\section{Vitamin C}

The ascorbic acid of ripe fruits was measured by volumetric method as per the reference from Sadasivsm and Manickam (1991). Following formula was used to calculate the ascorbic acid content.

Amount of ascorbic acid

$(\mathrm{mg} / 100 \mathrm{gm}$ sample $)=0.5 \mathrm{mg} \times \mathrm{V}$, $\mathrm{mlx} 12 \mathrm{ml} \times 100$

$$
\mathrm{V}_{1} \mathrm{ml} \times 5 \mathrm{ml} \times \mathrm{wt} \text {. of the sample }
$$

Where, V1= amount of dye consumed during the titration

$\mathrm{V} 2$ = amount of dye consumed when the supernatant was titrated with $4 \%$ oxalic acid

\section{Procedure used in the determination of Vitamin C}

Five $\mathrm{ml}$ of working standard was pipette out in to a $100 \mathrm{ml}$ of conical flask. Then $10 \mathrm{ml}$ of $4 \%$ oxalic acid was added and titration was done against the dye. This consumed amount of dye $\left(\mathrm{V}_{1} \mathrm{ml}\right)$ was the amount of $\mathrm{V}_{1}$ in formula. The amount of dye consumed till end point as represented by the appearance of pink coloration was equivalent to the amount of ascorbic acid.

Two $\mathrm{ml}$ of sample was extracted in $4 \%$ oxalic acid and $12 \mathrm{ml}$ of known volume was made and centrifuged. Five $\mathrm{ml}$ of this supernatant were pipette out to which 10 $\mathrm{ml}$ of $4 \%$ oxalic acid was added and titration was done against the dye. This consumed amount of dye was the amount of $\mathrm{V}_{2} \mathrm{ml}$ in formula.

\section{Color}

Color value of fruit skin was taken by using digital colorimeter (model: CHROMA METER CR-400, KONICA MINOLTA, INC).The measurement was taken from three different sides of the fruit $(n=3)$ from same predetermined points. The observations on $L^{*}, a^{*}$ and $b^{*}$ value wererecorded. The value "a*" refers the axis from green to red where positive value indicates red color and negative indicates green color, ' $b$ *' represents the blue-yellow axis and ' $\mathrm{L}^{* \prime}$ represents the lightness.

\section{Freshness}

Freshness of the fruit was measured using 1 to 5 hedonic scales, 1 for most fresh or least shriveled and 5 for least fresh or most shriveled. The panelist of 10 total scientists was involved in scoring the freshness of the fruit on the last day of storage under cool bot.

\section{Statistical analysis}

The collected data were arranged in MS-Excel and statistically analyzed with the help of R STAT. Mean separation was done by DMRT at 5\% level of significance (Gomez and Gomez, 1984).

\section{Results:}

\section{Physiological loss in weight (\%)}

The data pertaining to PLW of fruits is presented in figure 1 indicated the fruits packed in LDPE plastic without coating has the lowest PLW (1.69\%) followed by coconut oil coating $(10.83 \%)$ and castor oil coating $(12.12 \%)$ than rest of the treatments. The fruits without any treatment (control) showed the highest PLW $(15.72 \%)$ which was statistically at par with mustard oil coating (15.07\%).

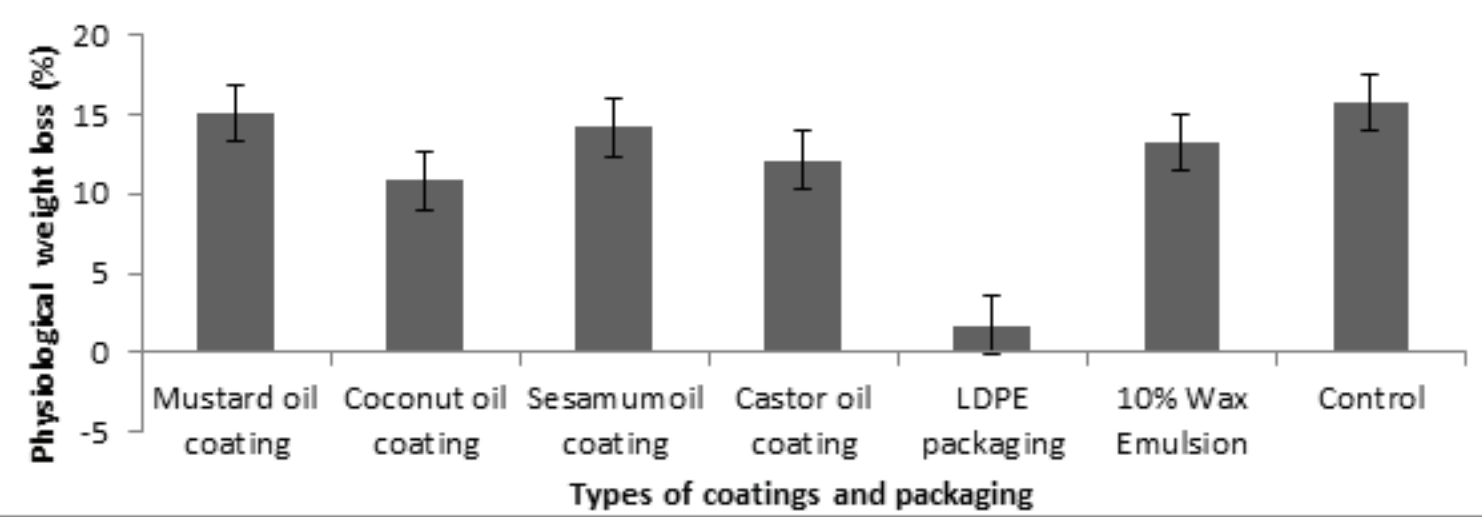

Figure 1: Physiological loss in weight of acid lime under ambient storage condition 


\section{Spoilage Loss (\%)}

Both visual and microscopic observation of the fruit was done to determine the spoilage loss and casual agents. The fruits coated with sesamum oil showed the highest spoilage loss (43.6\%) which was statistically at par with the fruit coated with mustard oil $(39.96 \%)$ whereas the lowest spoilage was found in the fruit packed in LDPE plastic bag $(5.17 \%)$ followed by coconut oil coating (10.45\%), castor oil coating $(12.44 \%), 10 \%$ wax emulsion (13.04\%) and control (19.94\%) respectively during the storage period (Figure 2). Based on the microscopic observation fruit was found infected by Penicillium sp. microorganisms.

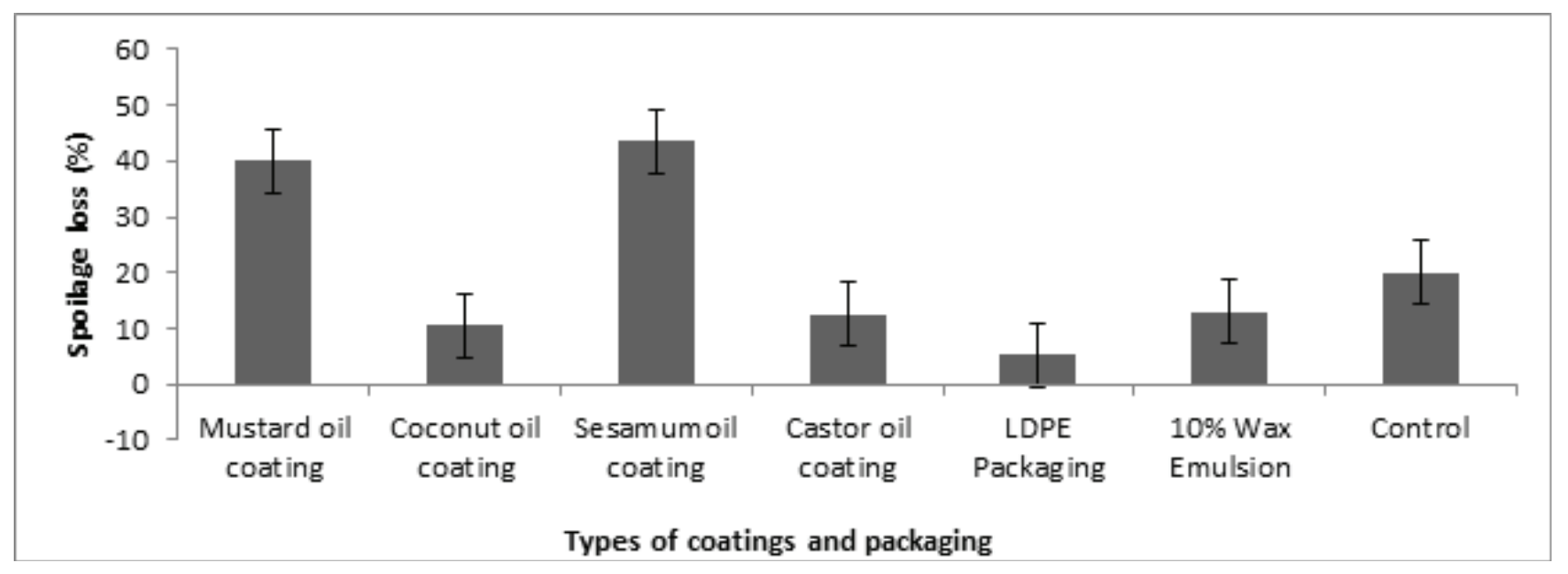

Figure 2: Spoilage loss of acid lime fruit under ambient storage condition

\section{TSS, TA and Vitamin C}

From the study it was found that the coating and packaging showed significant influence on the different postharvest quality parameters of acid lime as presented in Table 1 and 2. There was no influence of coating and packaging on TSS content of acid lime on $8^{\text {th }}, 16^{\text {th }}$ and $24^{\text {th }}$ day of storage. No influence of treatments was found on TA content of acid lime on $8^{\text {th }}$ day of storage. The TA content was significantly highest on $10 \%$ wax emulsion (6.77\%) followed byLDPE packaging (6.71 $\%$ ) on the $16^{\text {th }}$ day of storage. Similar trend was noticed on $16^{\text {th }}$ day of storage. However, significantly the highest TA content was noticed in LDPE packaging (6.46\%) followed by control $(6.24 \%)$ on $24^{\text {th }}$ day of storage whereas the lowest was observed in Castor oil coating (4.69\%). No significant change in vitamin $\mathrm{C}$ content of acid lime was observed on $8^{\text {th }}$ day of storage. On $16^{\text {th }}$ day of storage, the maximum vitamin $C$ content (61.35 $\mathrm{mg} / 100 \mathrm{~g}$ ) was observed in LDPE packaging followed by coconut oil coating $(59.99 \mathrm{mg} / 100 \mathrm{~g})$ whereas the minimum was observed in $10 \%$ wax emulsion (56.31 $\mathrm{mg} / 100 \mathrm{~g}$ ) which was statistically at par with mustard oil coating $(56.71 \mathrm{mg} / 100 \mathrm{~g})$.

\section{Color change}

Progressive color changes in $\mathrm{L}, \mathrm{a}^{*}$ and $\mathrm{b}^{*}$ values were observed in lime over the storage period (Table 9). The significant increase in $\mathrm{L}^{*}$ value was observed during the storage period where the maximum $L^{*}$ value was observed in the fruit packed in LDPE packaging on $8^{\text {th }}(51.95), 16^{\text {th }}(61.13)$ and $24^{\text {th }}(63.08)$ day of storage followed by fruit of control treatment. Rapid increase in "a*" values were observed in LDPE packaging (from -14.34 to -8.66 ) whereas smallest change in color was observed in Sesamum oil coating (from -15.24 to -13.74)followed by coconut oil coating (from -14.22 to $-12.35)$. No significant change in $a^{*}$ value was observed on $8^{\text {th }}$ day while the significant change was observed on $16^{\text {th }}$ and $24^{\text {th }}$ day of storage. The maximum $b^{*}$ values was noticed in LDPE packaging on $8^{\text {th }}(42.53)$, $16^{\text {th }}$ (50.40), and $24^{\text {th }}(48.71)$ day of storage respectively. The LDPE packaging was the mostly preferred for fruit freshness or appearance (1.33)for uniform yellow color development followed by coconut oil coating (2.66) and castor oil coating (3.33) for maintenances of relatively fresh and green color among all the methods under evaluation. 
Table 1: Effect of coatings and packaging on chemical quality of acid lime fruit under ambient storage condition.

\begin{tabular}{|l|l|l|l|l|l|l|l|l|l|}
\hline \multirow{3}{*}{ Treatment } & \multicolumn{3}{|c|}{ TSS ( ${ }^{\mathbf{0}}$ Brix) } & \multicolumn{3}{c|}{ TA (\%) } & \multicolumn{3}{c|}{ Vit (mg/100g) } \\
\cline { 2 - 10 } & $\begin{array}{c}\mathbf{8} \\
\text { DAS }\end{array}$ & $\begin{array}{c}\mathbf{1 6} \\
\text { DAS }\end{array}$ & $\begin{array}{c}\mathbf{2 4} \\
\text { DAS }\end{array}$ & $\begin{array}{c}\mathbf{8} \\
\text { DAS }\end{array}$ & $\begin{array}{c}\mathbf{1 6} \\
\text { DAS }\end{array}$ & $\begin{array}{c}\mathbf{2 4} \\
\text { DAS }\end{array}$ & $\mathbf{8}$ DAS & $\begin{array}{c}\text { 16 } \\
\text { DAS }\end{array}$ & 24 DAS \\
\hline Mustard oil coating & 6.86 & 7.10 & 7.13 & 6.42 & 6.37 & 5.89 & 60.51 & 56.71 & 55.46 \\
\hline Coconut oil coating & 6.90 & 6.96 & 7.10 & 6.21 & 5.57 & 5.42 & 62.44 & 59.99 & 58.81 \\
\hline Sesamum oil coating & 7.16 & 7.20 & 7.26 & 6.04 & 5.69 & 5.64 & 63.78 & 58.02 & 57.89 \\
\hline Castor oil coating & 6.50 & 7.46 & 7.50 & 5.44 & 4.81 & 4.69 & 61.88 & 58.32 & 57.32 \\
\hline LDPE packaging & 6.93 & 7.06 & 7.23 & 7.12 & 6.71 & 6.46 & 63.44 & 61.35 & 60.11 \\
\hline $10 \%$ wax emulsion & 6.93 & 7.33 & 7.40 & 7.15 & 6.77 & 5.86 & 59.63 & 56.31 & 56.36 \\
\hline Control & 7.00 & 7.30 & 7.53 & 6.95 & 6.55 & 6.24 & 61.26 & 58.02 & 53.83 \\
\hline Mean & 6.9 & 7.21 & 7.31 & 6.48 & 6.07 & 5.74 & 61.85 & 57.39 & 57.11 \\
\hline F-test & $\mathrm{NS}$ & $\mathrm{NS}$ & $\mathrm{NS}$ & $\mathrm{NS}$ & $* *$ & $*$ & $\mathrm{NS}$ & $* * *$ & $* * *$ \\
\hline LSD & 1.13 & 0.51 & 0.25 & 3.47 & 0.96 & 1.09 & 6.3 & 2.03 & 2.00 \\
\hline CV\% & 9.28 & 4.0 & 2.0 & 30.15 & 8.86 & 9.96 & 5.73 & 2.0 & 2.0 \\
\hline
\end{tabular}

$\mathrm{NS}, * * *$ and $* *$ indicate non-significant, significant at $\mathrm{P}<0.001$, and significant at $\mathrm{P}<0.005$, respectively.

Table 2: Effect of coatings and packaging on color changes $\left(\mathrm{L}^{*}, \mathrm{a}^{*}\right.$ and $\left.\mathrm{b}^{*}\right)$ and fruit freshness of acid lime after harvest under ambient storage condition.

\begin{tabular}{|c|c|c|c|c|c|c|c|c|c|c|}
\hline \multirow{3}{*}{ Treatment } & \multicolumn{9}{|c|}{ Color value } & \multirow{3}{*}{$\begin{array}{c}\text { Fresh- } \\
\text { ness } \\
(1-5)\end{array}$} \\
\hline & \multicolumn{3}{|c|}{$\mathbf{L}^{*}$} & \multicolumn{3}{|c|}{$a^{*}$} & \multicolumn{3}{|c|}{$\mathbf{b}^{*}$} & \\
\hline & $\begin{array}{c}8 \\
\text { DAS }\end{array}$ & $\begin{array}{c}16 \\
\text { DAS }\end{array}$ & $\begin{array}{c}24 \\
\text { DAS }\end{array}$ & 8 DAS & $\begin{array}{c}16 \\
\text { DAS }\end{array}$ & $\begin{array}{c}24 \\
\text { DAS }\end{array}$ & $\begin{array}{c}8 \\
\text { DAS }\end{array}$ & $\begin{array}{c}16 \\
\text { DAS }\end{array}$ & $\begin{array}{c}24 \\
\text { DAS }\end{array}$ & \\
\hline Mustard oil coating & 41.37 & 45.48 & 45.85 & -15.73 & -13.43 & -13.26 & 28.07 & 35.13 & 30.66 & 4.66 \\
\hline Coconut oil coating & 39.64 & 40.64 & 44.99 & -14.22 & -12.74 & -12.35 & 24.19 & 25.17 & 37.01 & 2.66 \\
\hline Sesamum oil coating & 40.25 & 43.58 & 49.13 & -15.24 & -13.79 & -13.74 & 28.02 & 32.79 & 46.45 & 4.33 \\
\hline Castor oil coating & 42.66 & 44.40 & 45.62 & -15.47 & -12.65 & -11.23 & 30.26 & 33.56 & 44.16 & 3.33 \\
\hline LDPE packaging & 51.95 & 61.13 & 63.08 & -14.34 & -8.25 & -8.66 & 42.53 & 50.40 & 48.71 & 1.33 \\
\hline $10 \%$ wax emulsion & 41.92 & 46.58 & 49.44 & -14.71 & -14.05 & -12.17 & 26.43 & 34.14 & 36.09 & 4.33 \\
\hline Control & 43.88 & 50.25 & 54.97 & -15.55 & -14.00 & -13.14 & 32.83 & 42.62 & 45.52 & 4.66 \\
\hline Mean & 43.10 & 47.44 & 50.44 & -15.04 & -12.70 & -12.08 & 30.3 & 36.26 & 41.23 & 3.61 \\
\hline F-test & $* *$ & $* * *$ & $* * *$ & NS & $* * *$ & $* *$ & $* *$ & $* * *$ & $* *$ & $* * *$ \\
\hline LSD & 6.23 & 6.04 & 6.41 & 2.37 & 1.22 & 2.04 & 8.02 & 7.06 & 8.08 & 3.61 \\
\hline $\mathrm{CV} \%$ & 8.13 & 7.16 & 7.13 & 8.87 & 5.5 & 9.49 & 14.86 & 10.94 & 11.02 & 13.14 \\
\hline
\end{tabular}

$\mathrm{NS}, * *$ and $* * *$ indicate non-significant, significant at $\mathrm{P}<0.05$, and significant at $\mathrm{P}<0.01$, respectively.

\section{Discussion}

Lower physiological loss in weight of lime fruits inside the LDPE packagingis expected considering the low rate of respiration because of decreased $\mathrm{O}_{2}$ and raised $\mathrm{CO}_{2}$ level along with high humidity within the plastic packaging (Poudel et al., 2018). The fruit coating act as a barrier in fruit respiration after harvest which reduce the diffusion of $\mathrm{O}_{2}$ and $\mathrm{CO}_{2}$ inside and out the fruit affecting the metabolism and hence prevent the water loss (Bhardwaj and Sen, 2003). The result of the present study is in linewith the findings in Mexican lime (Hernandez et al.,2015) and in mandarin (Rokayaet al.,2016). 
The minimum decay incidence inside the LDPE packaging might be due to lessvapour condensation inside the packaging. This finding is in line withGeyeret al. (2015). Similar results were observed by Jawandha, et al. (2014) who reported the minimum spoilage loss of Baramasi lemon fruits packed in LDPE packaging upto 50 days of storage period. The fruit coating with coconut oil reduces the chances of disease growth on the fruit surface by sealing thee stomatal openings and preventing the entry of pathogens inside the fruit. Similar results are reported by Meeterenand and Aliniaeifard (2016)and Nasrin et al.(2018). The spoilage loss in fruit coated with mustard and sesamum oil might be due to skin injury caused by higher concentration of oilson fruit surface. Similar case is illustrated by Bisenet al.(2012).

The rapid increase in TSS content in fruits under control treatment is due to faster loss of water, utilization of starch, polysaccharides as energy and conversion into soluble sugar and decreaseof titratable acidity is due consumption as energy source for respiration and other physiological processes after harvest (Wills et al., 1998). The reason for delayed increase in TSS content in LDPE packed fruit might be due to lower rate of water loss and starch and polysaccharides hydrolysis into soluble sugar. Reddy et al. (2008) observed that LDPE packaging as an effective material to minimize the increase in TSS content. The coatings delay the respiration rate by sealing the stomata pores and LPDE packaging by increasing the $\mathrm{CO} 2$ level inside the bag. Thus, the rate of utilization of sugar and organic acid of fruits in coconut oil coated fruit is low in present findings which are in line with findings of Yaman and Bayoindirli (2002). Similarly, Kulkarni et al. (2010) reported that the lower concentration of juice due to fruitcoatingleadsto reduction of dehydration as a result less increase in TSS content.In our present study, LDPE packaging showed the reduce rate of decrease in vitamin $\mathrm{C}$ content. This might be due to reduced amount of oxygen. The oxidation of ascorbic acid occurs in presence of oxygen in fruit. Reddy et al. (2008) also observed that the LDPE packaging was most effective in maintaining the highest level of vitamin $\mathrm{C}$ content in acid lime at normal room condition. Among all the coatings coconut oil was found to be beneficial in retaining the ascorbic acid content in fruit.The coating plays the positive role in preventing oxygen to enter into the fruit and reduce the oxidation of ascorbic acid (Oluwaseunet al., 2013). Our findings are similar to the findings of Nasrin et al. (2019) who reported that the coconut oil alone or in combination with Beewax and MAP showed the highest vitamin $\mathrm{C}$ content in lemon fruits. This study is also in accordance with the findings of Mahajan et al.(2015) and Iqbal et al. (2017).

The maximum increase in color coordinates $\left(\mathrm{L}^{*}, \mathrm{a}^{*}\right.$ and $\mathrm{b}^{*}$ ) was observed in LDPE packaging in our present findings which showed uniform color development in fruit. The present findings are in against of the findings of Moalemiyan and Ramaswamy (2012) and Maftoonazad and Ramaswamy(2015) who reported that the lowering of $\mathrm{O}_{2}$ and elevation of $\mathrm{CO}_{2}$ in the storage atmosphere inside packaging was found beneficial in preventing chlorophyll degradation. However, the similar finding was observed by Gidagiri et al. (2020) who reported that fruit treated with Chlorine-zeolite LDPE composite bag showed the most acceptable fruit color. The rapid change in fruit color inside the packaging in our study might be due to higher temperature inside the bag. The oxidation of color pigments along with water loss from the fruit skin cause the degradation of skin color The coating prevents the water loss from fruit surface and reduces the rate of color loss (Ribeiro et al., 2007;Maftoonazad and Ramaswamy, 2019).Poudel et al. (2018) elaborated that combined application of chemical and MAP helps to retain the fruit color.The fruit coated with coconut oil recorded green fruits up to $24^{\text {th }}$ days of storage (with lower color coordinates). Similar results were observed by Nasrin et al. (2019) who reported that coconut oil coating retain the fresh fruits with green and shiny skin color up to the 18 days of storage at ambient condition.

The freshness of the fruit is due to retention of water on fruit skin.In the present findings, LDPE packaging maintains the uniform yellow color on the fruit's skin which is preferred by Nepalese consumer. It may be due to increase in temperature and relative humidity inside the bag. This result is in line with thefindings obtained by Nasrin et al. (2019).Also the coconut oil coating is also found to be beneficial in maintaining the green color of the fruit for longer period in this study. This may be due to reduced respiration rate due to stomata pore sealing which delays the ripening.The minimum freshness observed in the fruits coated with mustard oil may be due to skin injury cause by oil concentration. Similar results are reported by Bisen et al. (2012). 


\section{Conclusion}

The coatings and packaging are the promising technologies to enhance the postharvest life of the acid lime.The study concluded that LDPE packaging and coconut oil showed the beneficialeffect to reduce the rate of degradation of internal and external quality of acid lime fruit.The recommended treatment materials are easily available, maintains longer shelf life, economic and safe for consumer's health. Thusit can be concluded that LDPE packaging and coconut oil coating can be used as an appropriate postharvest technologies to extend the shelf life of the acid lime fruits.

\section{Acknowledgement}

The authors would like to acknowledge Value Chain Development of fruits and vegetable Project in Nepal (VCDP) for providing for providing financial support to carry out the study.

\section{Declaration of conflict of interest and ethical approval:}

S. Poudel involved in designing, conducting experiment, analyzing and interpreting the results and preparing manuscript. I.P. Gautam involved in supervising the experimental work, providing guidelines for result interpretation and manuscript preparation. P.P. Khatiwada involved in providing guidelines to research conduct and manuscript preparation. D. Ghimire, S. Subedi, S. Pandey and M. Dhakal involved in conducting study and manuscript preparation. R. Regmi involved in data analysis and manuscript preparation.

The authors declare no conflicts of interest regarding publication of this manuscript.

\section{Reference}

Annual Report, (2019). Kalimati wholesale market. kalimati.gov.np.

Bhardwaj, R.L., \& Sen, N.Z. (2003). Zero energy cool chamber storage of mandarin (Citrus reticulate cv. Nagpur Santra). Journal of Food Science and Technology, 40(6),669-672.

Bisen, A., Pandey, S. K. \& Patel, N. (2012). Effect of skin coatings on prolonging shelf life of kagzi lime fruits (Citrus aurantifoliaSwingle). Journal of Food Science and Technology, 49(6), 753-759.
Geyer, M., Rux, G., Linke, M., Mahajan, P., Saengerlaub, S. \&Pant, A. (2015). Packaging of mushrooms in a humidity-regulating plastic tray for preventing water condensation. ActaHorticulture, 1079,153-158, doi: 10.17660/ ActaHortic.2015.1079.15.

Gidagiri , P., Jhaleghar, J., Jagadeesh, M. D., Babu, S. L., Meti, S., \&Padashetti,B. (2020). Studies on Zeolite-LDPE composite bags to extend the shelf life of acid lime fruits stored at ambient conditions. InternationalJournal of Current Microbiology and Applied Science, 9(2): 2673-2682. https://doi.org/10.20546/ ijcmas.2020.902.304

Gomez, K. A., \& Gomez, A. A. (1984). Statistical procedures for agricultural research. Newyork: John Wiley and Sons.

Hayat, F., Khan, M.N., Zafar, S.A.,Balal, R.M.,Nawaz, M.A., \& Malik, A.U. \&Saleem, B.A. (2017). Surface coating and modified atmosphere packaging enhances storage life and quality of 'Kaghzi lime'. Journal of Agricultural Science and Technology, 19, 1151-1160.

Hernandez, V.C.S., Huerta, N.C., Guzman, M.E.R., \&Gonzalez, M.M.R. (2015). Evaluation of post-harvest applications of gibberellic acid on the quality and shelf life of three varieties of Mexican lime. Serie horticultura, XXII(1), 1826.

Iqbal, J., Rab, A., Sajid, M., Shah, S.H.A., Bacha, S.A.S., Gul, G., \& Shah, S. (2017). Effect of partial coating of olive oil and storage duration on postharvest performance of sweet orange. Science International (Lahore), 29(3), 731-736.

Jawandha, S.K., Singh, H., Arora, A., \& Singh, J. (2014). Effect of modified atmosphere packaging on storage of Baramasi lemon (Citrus limonL. Burm). International Journal of Agriculture, Environment and Biotechnology,7(3), 635.

Kulkarni, S.G., Vijayanand, P. \& Shubha, L. (2010). Effect of processing of dates into dates juice concentrate and appraisal of its quality characteristics. Journal of Food Science Technology, 47, 157-161.

Ladaniya, M.S. (2015). Postharvest management of citrus fruit in south Asian countries. Acta Horticulture. 1065, 1669-1676. DOI: 10.17660/ ActaHorticulture.2015.1065.214 
Maftoonazad, N. \& Ramaswamy, H. (2015). Postharvest shelf-life extension of avocados using methyl cellulose-based coating. LWT-Food Science and Technology, 38, 617-624.

Maftoonazad, N. \& Ramaswamy, H.S. (2019). Application and Evaluation of a Pectin-Based Edible Coating Process for Quality Change Kinetics and Shelf-Life Extension of Lime Fruit (Citrus aurantifolium). Coating, 9, 285; doi:10.3390/coatings9050285

Mahajan, B.V.C., Dhillon, W.S., Kumar, M., \&Singh, B. (2015). Effect of different packaging films on shelf life and quality of peach under super and ordinary market conditions. Journal of Food Science and Technology, 52(6), 37563762. doi: 10.1007/s13197-014-1382-y. PMCID: PMC4444870

MoAD. (2018). Statistical informationon Nepalese agriculture. Ministryof Agricultural and Livestock Development, Singhadurbar, Kathmandu.

Moalemiyan, M. \& Ramaswamy, H. (2012). Quality retention and shelf-life extension in mediterranean cucumbers coated with a pectinbased film. Journal of Food Research, 1, 159.

Nasrin, T.A.A, Islam, M.N., Rahman, M.A., Arfin,M.S., \&Ullah,M.A.(2018). Evaluation of postharvest quality of edible coated mandarin at ambient storage, International Journal of Agriculture Research Innovation \& Technology, 8(1),18-25.

Nasrin, T.A.A, Rahman, M.A., Arfin,M.S., Islam M.N., \&Ullah, M.A. (2019). Effect ofnovel coconut oil and beeswax edible coating on postharvest quality of lemon at ambient storage,Journal of Agriculture and Food Research.https://doi. org/10.1016/j.jafr.2019.100019

Oluwaseun, A.C., Arowora, K. A., Bolajoko, F. O., Bunmi, J. A., \&Olagbaju, A. R. (2013). Effect of edible coating of carboxy methyl cellulose and corn starch on cucumber stored at ambient temperature. Asian Journal of Agriculture Biology,1,133-40.
Poudel, K.P. \& Khatiwada, P.P. (2020). Unpublished Document. Technical guidelines for citrus fruit entrepreneurship development.

Poudel, S., Shrestha, A.K., Mishra, K., Gotame, T.P., Regmi, R., \&Kafle, L. (2018). Maintenance of postharvest quality of litchi fruit by combined application of chemical and physical treatments. Journal of International Cooperation,13(2), 131-146

Reddy, V. B., Madhavi, G.B., Reddy,D.V., Reddy, V.C. \& Srinu, B. (2008). Effect of different packing materials on the shelf life and quality of acid lime (citrus aurantifolia swingla.) at room temperature. Journal of Dairying, Foods \& Home Sciences., 27 (3/4), 216 - 220.

Ribeiro, C., Vicente, A.A., Teixeira, J. A., \& Miranda, C. (2007). Optimization of edible coating composition to retard strawberry fruit senescence. Postharvest Biology Technology, 44, 63-70.

Rokaya, P.R., Baral, D.R., Gautam, D.M., Shrestha,A.K.,\&Paudyal, K.P. (2016). Effect of pre-harvest application of gibberellic acid on fruit quality and shelf life of mandarin (Citrus reticulata Blanco). American Journal of Plant Sciences, 7 (7), 1033-1039.

Sadasivam, S., and Manickam, A. (1991). Biochemical methods for agricultural sciences - Carbohydrates. Coimbatore: Newage International Publiser.

Wills, R.B.H., Mc-Glasson, B., Graham, D., \&Joyce, D. (1998). Postharvest: An Introduction to the Physiology and Handling of Fruits, Vegetables and Ornamentals. New South Wales: University of New South Wales Press Ltd.

Yaman, O. \&Bayoindirli, L.(2002). Effects of an edible coating and cold storage on shelf-life and quality of cherries. LWT-Food Science and Technology, 35(2), 46-150. 